\title{
Viral gastroenteritis: small round structured viruses, caliciviruses and astroviruses. Part I. The clinical and diagnostic perspective
}

Bristol Public Health Laboratory

E O Caul

Correspondence to: Dr E O Caul, Deputy Director, Bristol Public Health Laboratory, Myrtle Road, Kingsdown, Bristol BS2 8EL.

\author{
E Owen Caul
}

\begin{abstract}
Introduction
Routine UK surveillance of small round structured viruses (SRSVs), caliciviruses and astroviruses over many years, using electron microscopy, has provided important epidemiological data on their relative importance in human gastroenteritis. SRSVs have emerged as the major cause of epidemic non-bacterial gastroenteritis and are second only to rotaviruses in terms of morbidity and economic importance. Recent advances in the molecular characterisation of these viruses has provided new insights into their taxonomic status and has permitted the development of modern techniques by which these viruses can be investigated further. Sensitive molecular methodologies are now available to investigate the role and public health importance of these viruses in human disease as well as in food-borne outbreaks of gastroenteritis.
\end{abstract}

A complete analysis of the epidemiology of these viruses is presented in part II of this article, to be published in the next issue of this journal.

\section{Historical perspective}

A quarter of a century has passed since the original description of Norwalk virus as the aetiological agent of an outbreak of nonbacterial gastroenteritis which occurred in a primary school in the town of Norwalk, Ohio, USA.' The classic volunteer studies undertaken by American workers established Norwalk virus as an enteric pathogen and largely fulfilled Koch's postulates. ${ }^{23}$ Subsequently, additional volunteer studies were carried out using faecal material from two distinct, naturally occurring outbreaks of non-bacterial gastroenteritis in Hawaii and Montgomery County, USA. ${ }^{4}$ All of these human volunteer studies identified viruses which were morphologically similar on electron microscopic examination and produced clinically indistinguishable illness in humans. The agents responsible for these outbreaks were called Norwalk, Montgomery County and Hawaii viruses, respectively, reflecting their geographical origin. These studies represented a milestone in the investigation of human viral gastroenteritis and provided unique insights into the immunobiology and pathogenesis of a clinically and economically important group of viruses.

Following the discovery and description of Norwalk virus other workers applied electron microscopic techniques to the examination of faecal samples. Thus, the global application of electron microscopy resulted in major advances in our knowledge of viral gastroenteritis. ${ }^{4-7}$ Rotaviruses were identified as major pathogens in endemic childhood diarrhoea and the fastidious adenoviruses were added to the growing list of newly described diarrhoea viruses. The 1970 s represented a golden era in the discovery of diarrhoea related viruses and numerous reports described a wide range of small round viruses with varying particle diameters and surface morphology when examined in the electron microscope. Many studies applied the technique of immune electron microscopy (IEM), which masks the surface morphology of virus particles, and this often resulted in imprecise identification of the aetiology of non-bacterial gastroenteritis. ${ }^{5}$ In other instances small round viruses were identified from their classic surface morphology following negative staining and definitive descriptions of astroviruses and the classic caliciviruses were published. ${ }^{8-10}$

Attempts to propagate these newly described small round viruses in cell culture failed in these early investigative years and identification was based entirely on electron microscopy. As a result, opportunities to establish their taxonomic status were limited but there was a clear need to develop a surveillance system to establish the importance and role of these viruses in non-bacterial gastroenteritis. This was recognised in the UK and to produce standardised criteria for the uniform identification of smal round viruses an interim classification scheme was proposed. ${ }^{11}$

The classification scheme addressed comparative morphological and physical criteria resulting from the examination of established animal and human small round viruses in the electron microscope. This comparative study concluded that small round viruses could be readily subdivided into two distinct groups. One group of viruses were described as featureless viruses because a resolvable surface morphology in the electron microscope was not apparent and included both picornaviruses and parvovirus-like particles. The latter viruses had been incriminated in outbreaks of nonbacterial gastroenteritis ${ }^{1213}$ but definitive data establishing a causal role were lacking ${ }^{5}$ and this remains the situation to date.

The second group of small round viruses all possessed a distinctive surface morphology when viewed in the electron microscope. 


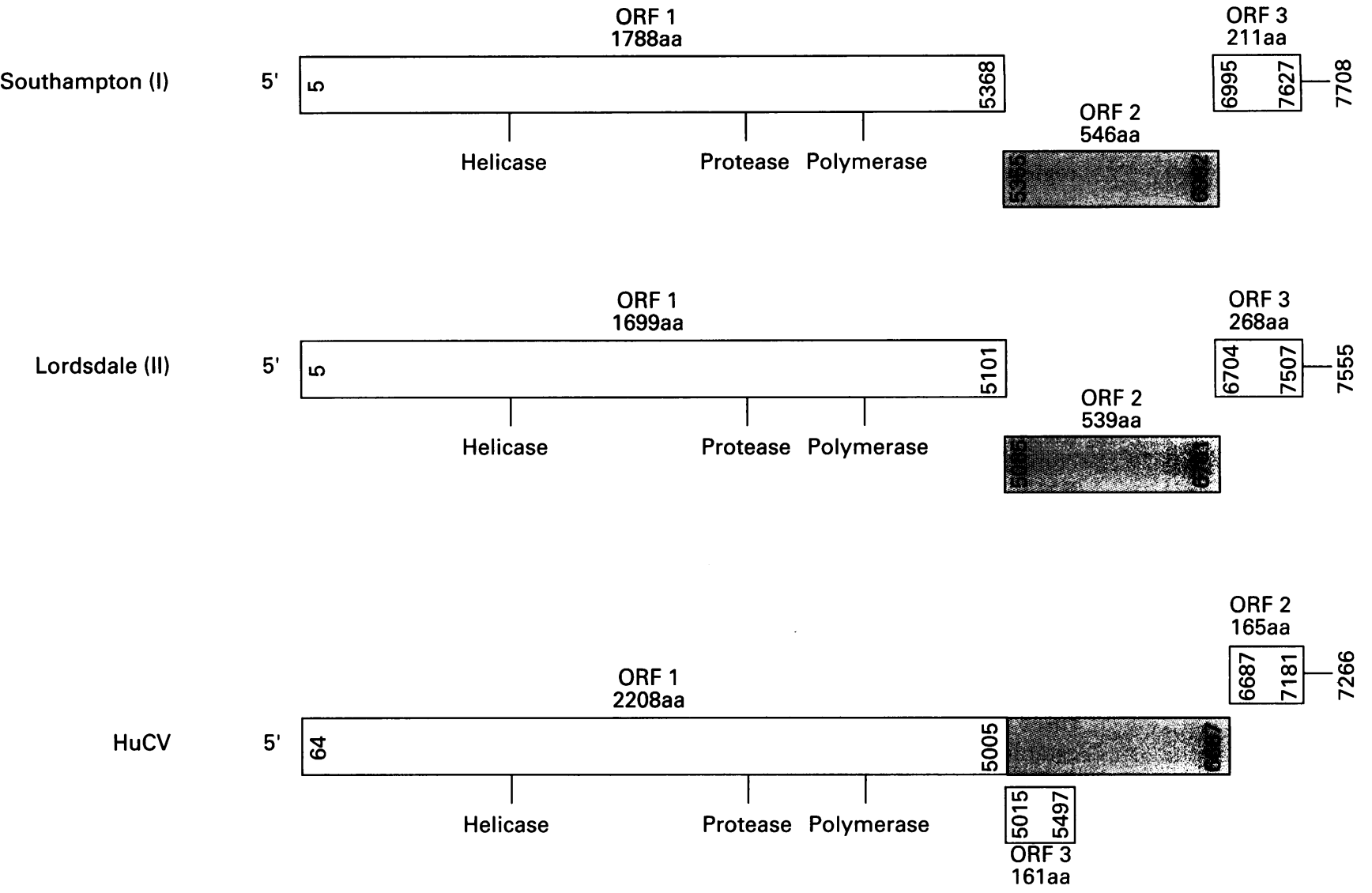

Figure 1 Organisation of the SRSV genome (genotypes I and II) and human calicivirus (HuCV). The open reading frames (ORF) predicted by sequence analysis are shown. The nucleotide coordinates of the predicted translation products are shown within the frames. The number of amino acids (aa) in the protein products are indicated outside the frames. The positions of $2 C$ helicase, $3 C$ protease and $3 D$ RNA polymerase motifs are indicated.

Often, this surface morphology was descriptive and included the previously described astroviruses and classic caliciviruses. Within this group other viruses, morphologically distinct from both astroviruses and caliciviruses, were recognised. These viruses shared a common reproducible morphology, lacking obvious geometric symmetry, and were described as possessing an amorphous surface structure with a ragged edge to the virus particles. They were represented by the prototype Norwalk virus as well as Montgomery County virus and Hawaii virus. To distinguish these latter viruses from astroviruses and caliciviruses and to aid national surveillance of diarrhoea viruses in the UK they were termed small round structured viruses. ${ }^{11}$ Subsequently, many other morphologically indistinguishable viruses have been identified and have often been named after the geographical setting in which the outbreak occurred-for example, Snow Mountain, Taunton, Toronto, Desert Storm, etc. ${ }^{4}$ This practice of naming SRSVs according to their geographical setting became a routine procedure $^{5}$ and persists to the present day. All of these morphologically indistinguishable viruses are currently classified as SRSVs and the term is interchangeable with Norwalk-like viruses. ${ }^{4}$ The SRSV group of viruses are now accepted as the most important causes of epidemic non-bacterial gastroenteritis in humans and have a similar clinical presentation.

An important aspect of the interim classification scheme was that it recognised fundamental morphological differences between SRSVs and the classic caliciviruses. Furthermore, these differences, which were also supported by epidemiological and immunobiological distinctions, would become even more apparent in future molecular studies. Although this morphological classification scheme was introduced into the UK (and subsequently elsewhere in the world) to aid national surveillance of diarrhoea viruses it was only considered an interim measure until more definitive criteria were established. It has, nevertheless, established important epidemiological data on the prevalence and importance of these small round viruses in viral gastroenteritis (see Part II) and has been supported by the recent molecular characterisation of the viruses involved.

\section{Taxonomy}

Recent advances in the genomic sequencing of these viruses has had a major impact and has provided surprising taxonomic information despite the inability to propagate SRSV and human caliciviruses in vitro.

Early studies in $1981^{14}$ demonstrated that SRSVs (Norwalk virus) are characterised by a single capsid protein of 59 kilodaltons and a RNA genome of positive polarity. The first report of a small fragment of the RNA polymerase gene (150 base pairs (bp)) of the Norwalk virus genome was published in 1990 
and this limited sequence information and further studies indicated that the viral genome was a single stranded, positive sense RNA of approximately 7.5 kilobases which was polyadenylated at its $3^{\prime}$ terminus. ${ }^{15} \mathrm{~A}$ short while later Matsui et $a l^{16}$ cloned an immunoreactive region of the Norwalk virus genome. Following these initial studies on Norwalk virus three complete genome sequences of SRSVs have been determined, which have resulted in the formal classification of SRSVs within the family Caliciviridiae. ${ }^{17-19}$ As a result of these elegant molecular studies several other reports documenting partial sequences covering the RNA polymerase and capsid regions in the $3^{\prime}$.half of the SRSV genome have been published. ${ }^{20-24} \mathrm{~A}$ comparison of the sequence data from the RNA polymerase and capsid regions of the genome has identified significant heterogeneity and has resulted in the division of SRSVs into two genetic groups. ${ }^{22-26}$ To date, two group $1^{1719}$ and one group $\mathrm{II}^{27}$ SRSVs have been fully sequenced and their genome organisation clearly distinguishes them from other positive stranded RNA viruses, such as the picornaviruses (fig 1). Genomic analysis of SRSVs has established that they should be classified within the family Caliciviridiae despite lacking the classic Star of David surface structure characteristic of human caliciviruses.

The classification of SRSVs within the Caliciviridiae family has raised interesting intellectual questions. Fundamental differences in morphology, epidemiology and immunobiology had already been recognised between SRSVs and the classic human caliciviruses. ${ }^{42829}$ In the light of these differences, genomic analysis of classic caliciviruses was considered an essential study to clarify further their relation to SRSVs. Initial reports on the sequence analysis of a small region of the RNA polymerase of classic caliciviruses suggested that they were genetically distinct from SRSVs. ${ }^{30}$ These findings were confirmed subsequently by Matson et al ${ }^{31}$ who also analysed a small region of the RNA polymerase of classic caliciviruses from the USA and Japan. As a result of these studies it became necessary to establish whether the genomic organisation of classic caliciviruses was similar to or distinct from SRSVs.

The complete genomic sequence of a single isolate of a classic human calicivirus has been recently reported, which revealed a unique organisation (fig 1) fundamentally different from that of SRSVs. ${ }^{32}$ Overall, the genome of classic caliciviruses is considerably smaller than any of the reported genomes of genetic group I or II SRSVs. The most interesting and fundamental difference which distinguishes the classic caliciviruses from SRSVs is in the organisation of the open reading frames (ORFs). In the case of the classic calicivirus the region of the genome encoding the capsid structural protein is found in the same reading frame as the non-structural proteins forming one long polyprotein which occupies over $90 \%$ of the total genome. ${ }^{32}$ This fused capsid polyprotein does not occur in the genome of SRSVs. ${ }^{33}$ Thus, in addition to the recognised differences between classic caliciviruses and SRSVs at the morphological, epidemiological and immunobiological levels, there are unique differences at the molecular level. Further analysis of the complete genomic sequence of classic Caliciviruses by other workers are now necessary to confirm these fundamental molecular differences. The genomic analysis reported to date indicates that the classic human enteric caliciviruses belong to a separate subgroup distinct from SRSVs within the family Caliciviridiae. Such a division is essential to maintain the important epidemiological role of SRSVs as major causes of epidemic non-bacterial gastroenteritis in contradistinction to the role of the classic caliciviruses in human disease.

The taxonomic status of astroviruses has also been considerably advanced with the recent reports of the complete genomic sequence of two serotypes. ${ }^{3435}$ The overall genome organisation, represented by three large overlapping reading frames (ORFs $1 \mathrm{a}, 1 \mathrm{~b}$ and 2), are similar for both serotypes. ORF 2 is located at the 3 ' terminus of the genome and codes for a large capsid polypeptide by means of a 90 kilodalton precursor polypeptide. In the presence of trypsin this large capsid polypeptide is cleaved into three fragments of molecular weights 31,29 and 20 kilodaltons. As a result of their molecular characterisation it has been proposed recently that astroviruses are a separate group of non-enveloped viruses within their own family Astroviridiae. ${ }^{36}$

\section{Clinical aspects}

The symptoms arising from infections caused by SRSV, calicivirus and astroviruses are in general mild and self-limiting, and mortality in the absence of other confounding factors is extremely rare. Some reports have documented a more severe gastroenteritis with significant dehydration as a result of diarrhoea or vomiting, or both. The clinical presentation, for all three viruses, in children is similar and does not permit any clinical distinction to be made. In contrast, SRSV infections in adults commonly present as explosive projectile vomiting or diarrhoea, or both, ${ }^{47}$ and this, in conjunction with its acute onset and high secondary attack rate, permits a presumptive clinical diagnosis of SRSV infection. Subclinical infections, particularly with astroviruses and caliciviruses, are common in children.

The faecal/oral route is established as an important mode of transmission giving rise to person to person spread of SRSVs, caliciviruses and astroviruses. Transmission is followed by an incubation period of 15 to 50 hours for SRSV (dose dependent) ${ }^{38}$ with a mean of 24 to 48 hours. ${ }^{45} \mathrm{~A}$ similar incubation period is applicable to caliciviruses but astroviruses have a longer incubation period of about four days. This longer incubation period can be useful in making clinical distinctions between these and the other diarrhoea viruses (other than enteric adenoviruses) and also helps in control of infection strategies in closed communities.

The common observation that SRSV infections give rise to projectile vomiting adds an 
additional dimension to the established transmission routes for this virus. Thus, it is now recognised that virus containing vomit is also an important vehicle for the transmission of SRSVs where mechanical transmission (hand/ mouth) from the vomit contaminated environment may occur. ${ }^{3739}$ Airborne transmission arising from aerosolised vomit following projectile vomiting is also a potential problem, ${ }^{40}$ although classic respiratory spread has not been documented. ${ }^{37}$ All of these circumstances would explain the explosive outbreaks of SRSV that have been documented in semi-closed communities which cannot be explained by faecal/oral spread alone.

\section{Pathogenesis}

Within our current knowledge SRSVs, caliciviruses and astroviruses are transmitted to humans by the oral route where they reach the small intestine via the stomach. Their ability to retain infectivity after passage through the stomach implies that they are all acid stable. Most of our knowledge on the replication of SRSVs in the small intestine is derived from the classic volunteer studies carried out by American workers using the Norwalk, Montgomery County and Hawaii SRSVs. Infected volunteers have provided intestinal biopsy samples $^{2-4142}$ which have been studied at the light and electron microscopic level. In general, virus replication occurs in the mucosal epithelium of the small intestine, resulting in a broadening and flattening of the villi although direct evidence of viral maturation is lacking. Damage to mucosal epithelial cells results in a crypt cell hyperplasia. Ultrastructural studies by transmission electron microscopy have demonstrated alterations in the rough and smooth endoplasmic reticulum with a concomitant increase in multi-vesiculate bodies. Although microvilli were profoundly shortened, and undefined amorphous electron dense material was observed in the intercellular spaces, it was notable that virus particles were not observed in the affected mucosal epithelium. Detailed studies of astrovirus and calicivirus infections in humans documenting the sequential events arising from virus replication in the small intestine are not available, although astrovirus particles have been demonstrated in the mucosal epithelium of an infected child. ${ }^{43}$ Comparative studies in animals infected with astroviruses ${ }^{44}$ and caliciviruses $^{45}$ suggest that the events in vivo following SRSV infection in humans are also broadly applicable to human astrovirus and calicivirus infections.

\section{Laboratory diagnosis}

ELECTRON MICROSCOPY

Historically, and because all of these viruses have been difficult or impossible to grow in cell culture, electron microscopy has been fundamental in the production of national surveil- lance data in the UK. All three viruses have a distinct and identifiable surface morphology (fig 2) which permits confident diagnosis when apparent. Thus, detailed descriptions of the morphology of SRSV, caliciviruses and astroviruses have been published. ${ }^{4511}$ In general, the recognition of cup-shaped indentations on the surface of caliciviruses permits definitive identification. Similarly, the five/six pointed surface star on up to $20 \%$ of astrovirus particles permits a distinction to be drawn between them and caliciviruses. The reproducible amorphous appearance of SRSVs and the lack of an apparent organised geometric symmetry also permits definitive identification in reliable hands. All of these distinctive morphological appearances have been the mainstay of diagnostic electron microscopy in the UK and this has produced reliable and comprehensive national surveillance data over many years. Currently, new immunoassays are being developed which will eventually supersede the need for electron microscopy and the recent exciting molecular developments will impact further on this historical need. Nevertheless, electron microscopy will retain an important role for the continued surveillance of antigenic variants of SRSV in outbreaks of non-bacterial gastroenteritis, as a catch-all system for all diarrhoea viruses and as a gold standard in the development of new technology.

\section{IMMUNOASSAYS}

In general, immunoassays for the detection of all these small round RNA viruses are not available for routine diagnosis. Nakata et al ${ }^{46}$ have developed a solid phase radioimmunoassay for the detection of caliciviruses in human stools and have shown that this assay, which utilises a polyclonal antibody, is more sensitive than electron microscopy. Conversion of this assay to an enzyme immunoassay (EIA) format has made it more user friendly without any significant loss in sensitivity. ${ }^{47}$ It is not yet available to the routine laboratory but presumably will be in the future, provided a continuous supply of polyclonal antibodies is available. The preparation of monoclonal antibodies to the astrovirus group antigen has permitted the development of an EIA which detected all astroviruses grown in cell culture. ${ }^{48}$ Modifications to this assay has resulted in an EIA which detects astroviruses directly in stool samples ${ }^{49}$ and was shown to be as sensitive and specific as IEM. The availability of EIAs for the detection of both caliciviruses and astroviruses will enhance our knowledge of the epidemiology and clinical importance of these two viruses.

In contrast, the development of immunoassays for the detection of all antigenic variants of SRSVs in stool samples remains an objective for the future. This is largely because of the considerable variation in the polymerase region of SRSV genomes as well as the recognised capsid diversity. Thus, expression of the Norwalk virus capsid in baculovirus has permitted the development of assays which are specific to Norwalk virus ${ }^{50}$ but do not permit 

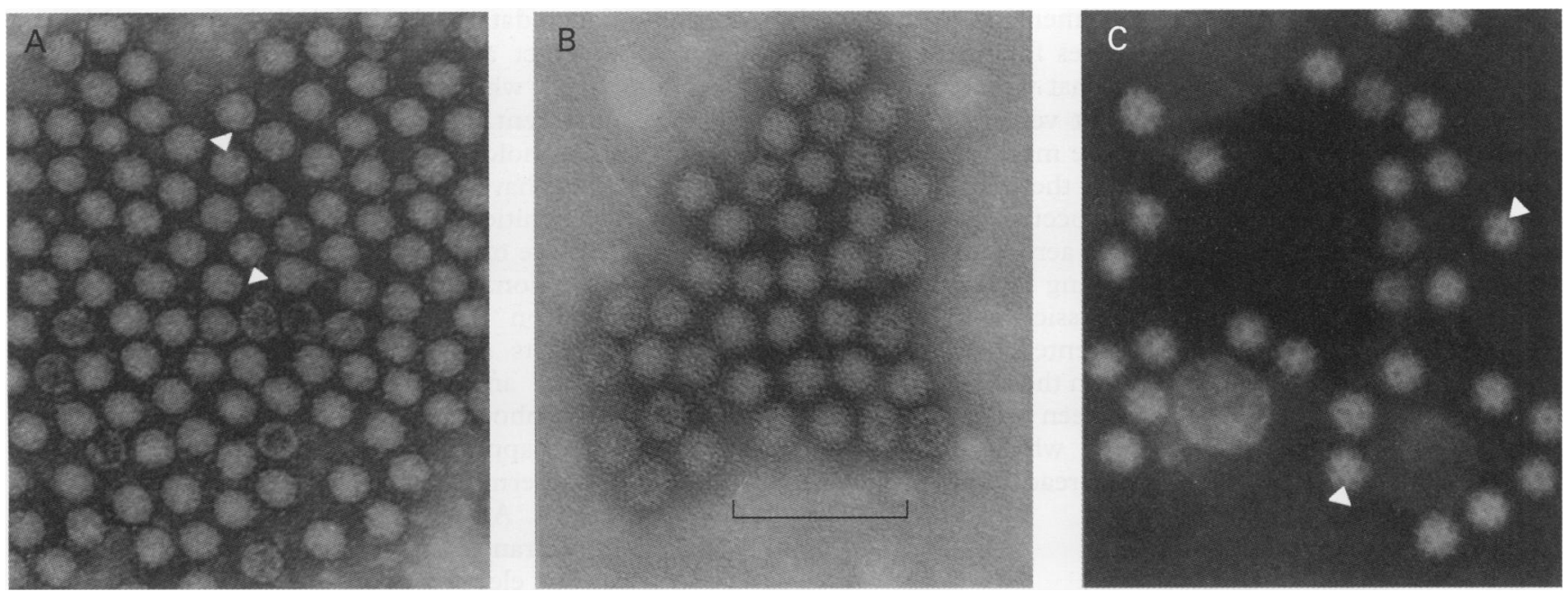

Figure 2 (A) Astrovirus, (B) SRSV and (C) human caliciviruses negatively stained with 1.5\% phosphotungstic acid. Note (arrows) star-shaped morphology on astrovirus particles $(A)$ and cup-shaped indentions on caliciviruses $(C)$. Bar represents $100 \mathrm{~nm}$.

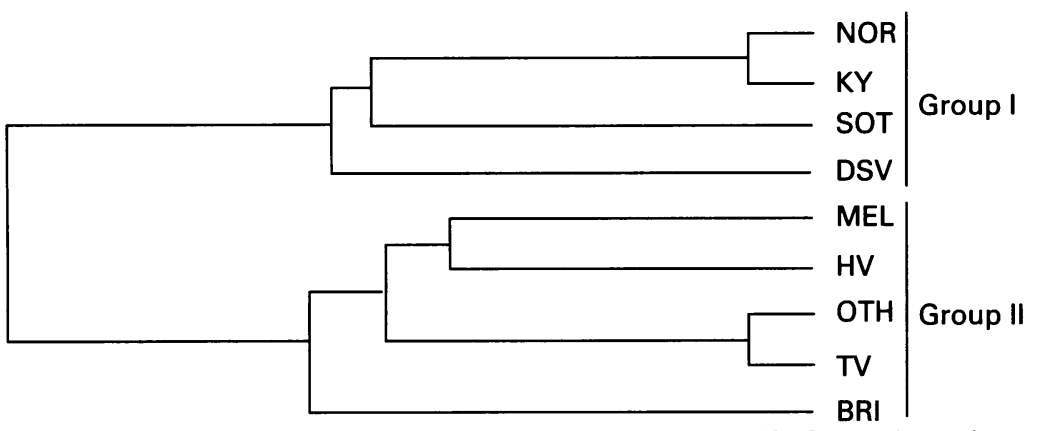

Figure 3 Dendrogram showing the genetic relations of SRSV capsids. Comparisons of ORF 2 (capsid) amino acid sequences by the multiple alignment Clustal method reveals two SRSV genetic groups. Horizontal branch lengths are proportional to the extent of capsid sequence divergence. The SRSVs represented are NORWALK/68/US (NOR), KY-89/89/7 (KY), SOUTHAMPTON/91/UK (SOT), Desert Shield 395 (DSV), MELKSHAM/89/UK (MEL), Hawaii virus (HV), OTH- 25/89/f (OTH), Toronto virus (TV), and BRISTOL/93/UK (BRI).

the detection of antigenically distinct SRSVs. As Norwalk virus is no longer circulating in the community this assay has a limited application to diagnostic laboratories. There is a clear need to develop a catch-all SRSV assay with high sensitivity and specificity. Nevertheless, the expression of all antigenically distinct SRSV capsids $^{20-245152}$ will be useful for the development of immunoassays for antigen detection. Currently, the use of recombinant Norwalk virus capsids in an EIA format in seroepidemiological studies has demonstrated a high prevalence of antibody. ${ }^{5253}$ There is little evidence that Norwalk virus is circulating in the community, suggesting that this assay may be detecting heterologous rather than homologous responses arising from antigenically distinct SRSVs. Similar problems may also apply to the use of other antigenically distinct recombinant capsids when utilised in an EIA format.

\section{MOLECULAR DIAGNOSIS}

The application of reverse transcription polymerase chain reaction (RT-PCR) to the diagnosis of SRSV infections has become a reality following the characterisation of the viral genome. Studies to date have demon- strated a surprising degree of heterogeneity both in the RNA polymerase and capsid regions of SRSVs, permitting subdivision into two genetic groups (fig 3). Surveillance of outbreaks in the Bristol Laboratory have identified genotype II SRSVs as the predominant strains currently circulating in the UK (unpublished data). As a result of these studies it has been necessary to reassess, refine and design new primers continually, as required. It remains important to monitor continually the circulation of SRSVs in the general population, at least in the short term, to achieve maximum sensitivity from the use of RT-PCR. Molecular epidemiology is now a powerful tool for the investigation of point source outbreaks related to food/food-handlers, shellfish and water supplies $^{54-56}$ and also to monitor the spread of SRSVs within semi-closed communities. ${ }^{57}$ The increased sensitivity of RT-PCR for detecting SRSVs in human faecal samples collected late after onset of illness (more than three days) will enhance our epidemiological knowledge of these important viruses. ${ }^{58}$

Now that the complete genomic sequence of astroviruses and the classic caliciviruses have been characterised, similar molecular techniques using RT-PCR can be applied to these viruses which will also enhance our knowledge of their importance in gastrointestinal disease. The presence of inhibitors of PCR in some faecal samples remains a problem for all these viruses and needs to be addressed. In the meantime, electron microscopy will retain an important role as a catch-all system and also as a tool to respond to the urgent differential diagnosis of outbreaks of gastroenteritis in semi-closed communities.

SEROLOGY

It is unlikely that laboratories will need to use a serological assay for the diagnosis of any of these small round viruses in the future. However, the production of viral capsids in baculovirus expression systems will allow seroepidemiological studies to be carried out, provided that assays are developed which will

.


detect homologous rather than heterologous responses in human serum. Such assays may also be useful for retrospective epidemiological investigations where antigen detection or molecular techniques, or both, have failed to identify an aetiological agent.

\section{Conclusions}

The recent molecular characterisation of the small round diarrhoea viruses has had important taxonomic implications. It is apparent that SRSVs and the classic human caliciviruses are distinct subgroups within the family Caliciviridiae.

Diagnostic detection systems using RT-PCR are now available for all of these viruses and will particularly enhance our knowledge of the diversity of circulating strains and the importance of SRSVs in non-bacterial gastroenteritis. Molecular approaches can now be applied to the investigation of point source outbreaks of non-bacterial gastroenteritis, providing us with a powerful molecular epidemiological method for establishing the source of an outbreak. The development of assays based on recombinant antigens is now feasible and will be an important objective for the future to reduce the burden on electron microscopy and provide a laboratory friendly assay for diagnosis and large scale population surveillance.

1 Kapikian AZ, Wyatt RG, Dolin R, Thornhill TS, Kalica AR, Chanock RM. Visualisation by immune electron microscopy of a $27-\mathrm{nm}$ particle associated with infectious nonbacterial gastroenteritis. F Virol 1972;10:1075-81.

2 Agus SG, Dolin R, Wyatt RG, Tousimis AJ, Northrup RS. Acute infectious nonbacterial gastroenteritis: intestinal histopathology. Histologic and enzymatic alterations during illness produced by the Norwalk agent in man. Ann Intern Med 1973;79:18-25.

3 Schreiber DS, Blacklow NR, Trier S. The mucosal lesion of the proximal small intestine in acute infectious nonbacterial gastroenteritis. $N$ Engl f Med 1973;288:1318-23

4 Kapikian AZ (ed). Norwalk and Norwalk-like viruses. In: Viral infections of the gastrointestinal tract. New York: Marce Dekker, 1994:471-518.

5 Caul EO. Small round human fecal viruses. In: Pattison JR ed. Parvoviruses and human disease. Boca Raton, Florida: ed. Parvoviruses and human

6 Cukor G, Blacklow NR. Human viral gastroenteritis. Microbiol Rev 1984;48:157-79.

7 Christensen ML. Human viral gastroenteritis. Clin Microbiol Rev 1989;2:51-89.

8 Madeley CR. Comparison of the features of astroviruses and caliciviruses seen in samples of faeces by electron microscopy. F Infect Dis 1979;139:519-23.

9 Madeley CR, Cosgrove BP. $28 \mathrm{~nm}$ particles in faeces in infantile gastroenteritis. Lancet 1975;i:451-2.

10 Madeley CR, Cosgrove BP. Caliciviruses in man. Lancet 1976;i: 199-200.

11 Caul EO, Appleton $H$. The electron microscopical and physical characteristics of small round human fecal viruses: an interim scheme for classification. $\mathcal{f}$ Med Virol 1982;9: 257-65.

12 Appleton H, Buckley M, Thom BT, Cotton JL, Henderson S. Virus-like particles in winter vomiting disease. Lancet 1977;i:409-11.

13 Appleton H, Pereira MS. A possible virus etiology in outbreaks of food-poisoning from cockles. Lancet 1977;i: 780-1.

14 Greenberg HB, Valdesuso JR, Kalica AR, Wyatt RG, virus. $\mathcal{F}$ Virol $191 ; 37: 994-9$

15 Jiang X, Graham Y, Wang K, Estes MK. Norwalk virus genome cloning and characterization. Science 1990;250: genome

16 Matsui SM, Kim JP, Greenberg HB, Su W, Sun Q, Johnson $P V$, et al. The isolation and characterization of a Norwalk virus-specific cDNA. $\mathcal{F}$ Clin Invest 1991;87:1456-61.

17 Lambden PR, Caul EO, Ashley CR, Clarke IN. Sequence and genome organisation of a human small roundstructured (Norwalk-like) virus. Science 1993;259:516-19.
18 Lambden PR, Liu BL, Clarke IN. A conserved sequence motif at the 5' terminus of the Southampton virus genome
is characteristic of the Caliciviridae. Virus Genes 1995;10: 149-52.

19 Jiang X, Wang M, Wang K, Estes MK. Sequence and genomic organization of Norwalk virus. Virology 1993;195:51-61.

20 Lew JF, Kapikian AZ, Jiang X, Estes MK, Green KY. Molecular characterization and expression of the capsid protein of a Norwalk-like virus recovered from a Desert Shield troop with gastroenteritis. Virology 1994;200:319-25.

21 Lew JF, Kapikian AZ, Valdesuso, Green KY. Molecular characterization of Hawaii virus and other Norwalk-like viruses: evidence for genetic polymorphism among human caliciviruses. F Infect Dis 1994;170:535-42.

22 Green SM, Dingle KE, Lambden PR, Caul EO, Ashley CR Clarke IN. Human enteric Caliciviridiae: a new prevalent small round-structured virus group defined by RNAdependent RNA polymerase and capsid diversity. $\mathcal{F}$ Gen Virol 1994;75:1883-8.

23 Green SM, Lambden PR, Caul EO, Ashley CR, Clarke IN. Capsid diversity in small round-structured viruses: molecular characterisation of an antigenically distinct human enteric calicivirus. Virus Res 1995;37:271-83.

24 Wang J, Jiang X, Madore HP, Gray J, Desselberger U, Ando $\mathrm{T}$, et al Sequence diversity of small, round-structured viruses in the Norwalk virus group. $f$ Virol 1994;68:5982-90.

25 Cubitt WD, Jiang XJ, Wang J, Estes MK. Sequence similarity of human caliciviruses and small round structured ity of human caliciviruses and smal
viruses. $\mathcal{f}$ Med Virol 1994;43:252-8.

26 Ando T, Mulders MN, Lewis DC, Estes MK, Monroe SS Glass RI. Comparison of the polymerase region of small round structured virus strains previously classified in three antigenic types by solid-phase immune electron microscopy. Arch Virol 1994;135:217-26.

27 Dingle KE, Lambden PR, Caul EO, Clarke IN. Human enteric Caliciviridae: the complete genome sequence and expression of virus-like particles from a genetic group II expression of virus-like particles from a genetic group 11

28 Wyatt RG, Dolin R, Blacklow NR, DuPont HL, Buscho RF, Thornhill TS, et al. Comparison of three agents of acute infectious nonbacterial gastroenteritis by cross-challenge in volunteers. F Infect Dis 1974;129:709-14.

29 Parrino TA, Schreiber DS, Trier JS, Kapikian AZ, Blacklow NR. Clinical immunity in acute gastroenteritis caused by Norwalk agent. $N$ Engl f Med 1977;297:86-9.

30 Lambden PR, Caul EO, Ashley CR, Clarke IN. Human enteric caliciviruses are genetically distinct from small round structured viruses. Lancet 1994;343:666-7.

31 Matson DO, Zhong WM, Nakata K, Jiang X, Pickering LK, Chiba S, et al. Molecular characterization of a human calicivirus with sequence relationships closer to animal caliciviruses than other known human caliciviruses. $f \mathrm{Med}$ Virol 1995;45:215-22.

32 Liu BL, Clarke IN, Caul EO, Lambden PR. Human enteric caliciviruses have a unique genome structure and are distinct from the Norwalk-like viruses. Arch Virol 1995; 140: $1345-56$

33 Clarke IN, Lambden PR, Caul EO. Human enteric RNA viruses: Caliciviruses and astroviruses. In: Collier $\mathrm{L}$, ed. Topley and Wilson. Microbiology and microbial infections. 9th Topley and Wilson. Microbiology and microbial infect

34 Jiang B, Monroe SS, Koonin EV, Stine SE, Glass RI. RNA sequence of astrovirus: Distinctive genomic organization and a putative retrovirus-like ribosomal frame-shifting signal that directs the viral replicase synthesis. Proc Natl Acad Sci USA 1993;90: 10539-43.

35 Willcocks MM, Brown TDK, Madeley CR, Carter MJ. The complete sequence of a human astrovirus. 7 Gen Virol 1994;75:1785-8.

36 Monroe SS, Jiang B, Stine SE, Koopmans M, Glass RI Subgenomic RNA sequence of human astrovirus supports classification of Astroviridae as a new family of RNA viruses. $\mathcal{F}$ Virol 1993;6:3611-14.

37 Caul EO. Small round structured viruses-airborne transmission and hospital control. Lancet 1994;343:1240-2

38 Blacklow NR, Herrmann JE. Norwalk virus. Proceedings of the Ninth BSG SK\&F International Workshop; 1988 Oct 2-4. Windsor, UK. Welwyn Garden City; Smith Klin and French, 1988:65-9.

39 Chadwick PR, McCann R. Transmission of a small round structured virus by vomiting during a hospital outbreak of gastroenteritis. f Hosp Infect 1994;26:251-9.

40 Sawyer LA, Murphy J, Kaplan JE, Pinsky PF, Chacon D Walmsley S, et al. 25- to $30-\mathrm{nm}$ virus particle associated with a hospital outbreak of acute gastroenteritis with evidence for airborne transmission. $\mathrm{Am} \quad \mathcal{f}$ Epidemio evidence for airbo

41 Dolin R, Levy AG, Wyatt RG, Thornhill TS, Gardner JD. Viral gastroenteritis induced by the Hawaii agent: jejunal histopathology and sero-response. Am f Med 1975;59: 761-9

42 Schreiber DS, Blacklow NR, Trier S. The small intestina lesion induced by the Hawail agent in infectious nonbacterial gastroenteritis. F Infect Dis 1974;142:705-8.

43 Phillips AD, Rice SJ, Walker-Smith JA. Astrovirus within human small intestinal mucosa. Gut 1982;23:A923-4.

44 Snodgrass DR, Angus KW, Gray EW, Menzies JD, Paul G. Pathogenesis of diarrhoea caused by astrovirus infections in lambs. Arch Virol 1979;60:217-26.

45 Hall GA, Bridger JC, Brooker BE, Parsons KR, OrmerodLesions of gnotobiotic calves experimentally infected with Lesions of gnotobiotic calves experimentally infected with
calicivirus-like (Newbury) agent. Vet Pathol 1984;21:208-15.

46 Nakata S, Ciba S, Teerashima H, Sakuma Y, Kogasaka R Nakao T. Microtiter solid-phase radioimmunoassay for 
detection of human calicivirus in stools. $\mathcal{f}$ Clin Microbiol 1983;17:198-201.

47 Nakata S, Estes MK, Chiba S. Detection of human calicivirus antigen and antibody by enzyme-linked immunosorbent assays. $\mathcal{F}$ Clin Microbiol 1988;26:2001-5.

48 Herrmann JE, Hudson RW, Perron-Henry DM, Kurtz JB Blacklow NR. Antigenic characterization of cell-cultivated astrovirus serotypes and development of astrovirus-specific monoclonal antibodies. F Infect Dis 1988;158:182-5.

9 Herrmann JE, Nowak NA, Perron-Henry DM, Hudson RW, Cubitt WD, Blacklow NR. Diagnosis of astrovirus gastroenteritis by antigen detection with monoclonal antibodies. F Infect Dis 1990;161:226-9.

50 Jiang X, Wang M, Graham DY, Estes MK. Expression, selfassembly, and antigenicity of the Norwalk virus capsid protein. $\mathcal{F}$ Virol 1992;66:6527-32.

51 Jiang X, Matson DO, Ruiz-Palacios GM, Ju J, Treanon J, Pickering LK. Expression, self-assembly, and antigenicity of a Snow Mountain Agent-like calicivirus capsid protein. $f$ of a Snow Mountain Agent-like

52 Treanor J, Jiang X, Madore HP, Estes MK. Subclassspecific serum antibody responses to recombinant Norwalk virus capsid antigen (rNV) in adults infected with Norwalk, Snow mountain, or Hawaii virus. F Clin Microbiol 1993;31: $1630-4$.
53 Gray J, Jiang X, Morgan-Capner P, Desselberger U, Estes MK. Prevalence of antibodies to Norwalk virus in England: detection by enzyme-linked immunosorbent assay using baculovirus-expressed Norwalk virus capsid antigen. $f$ Clin Maculovirus-expressed Norwalk virus capsid antigen. $f$ Clin
Microbil 1993;31:1022-5.

54 Atmar RL, Metcalf TG, Neill FH, Estes MK. Detection of enteric viruses in oysters by using the polymerase chain-reaction. App Env Microbiol 1993;59:631-5.

55 Glass RI. Chaper 2. Outbreaks of food-borne viral gastroenteritis in the U.S. In: Workshop on food-borne viral infections. Advisory Committee on the Microbiological Safety of Food. London: HMSO, 1994:37-43.

56 Lees DN, Henshilwood K, Green J, Gallimore CI, Brown DW. Detection of small round structured viruses in shellfish by reverse transcription-PCR. App Environ Microbiol 1995;61:4418-24.

57 Green SM, Lambden PR, Deng Y, Lowes JA, Lineham S, Bushell J, et al. Polymerase chain reaction detection of small round-structured viruses from two related hospital outbreaks of gastroenteritis using inosine-containing primers. 7 Med Virol 1995;45:192-202.

58 Green J, Hale AD, Brown DWG. Recent developments in the detection and characterisation of small round structhe detection and characterisation of small round struc-
tured viruses. PHLS Microbiology Digest 1995;12:219-22. 